\title{
A Comparison of Visual, Brainstem Auditory, and Somatosensory Evoked Potentials in Multiple Sclerosis
}

\author{
S.J. PURVES, M.D. LOW, J. GALlowAY and B. REEVES
}

SUMMARY: Multimodality evoked potentials testing including PVEPS, SEPs and $B A E P s$ was done in 112 patients who were known or suspected to have multiple sclerosis. The incidence of abnormal evoked potential findings in each of these systems was considered in patients in the different diagnostic categories of M.S. Results were also evaluated with respect to the presence of abnormal clinical visual, somatosensory, or brainstem signs. The PVEP was found to be the most frequently abnormal even in patients without clinical involvement in the visual system $45 \%$ of patients with definite, probable, or possible

RÉSUMÉ: Nous avons étudié, chez $/ / 2$ patients au diagnostic connu ou présumé de sclérose en plaques, les potentiels évoqués multimodaux, incluant les PVEP. SEP et BAEP. Nous avons étudié l'incidence de potentiels évoqués anormaux pour les différentes catégories diagnostiques de sclérose en plaques. Ces résultats furent également évalués par rapport à la présence de signes cliniques anormaux visuels, somatosensitifs ou du tronc cérébral. Le PVEP fut trouvé le plus fréquemment anormal, même chez des
M.S.), the SEP was less frequently abnormal in the absence of clinical signs (35\% in patients with M.S.), and the BAEP showed the lowest frequency of abnormalities in patients without brainstem signs (14\% in patients with M.S.). Combining the three types of evoked potentials significantly increased the percentage of $M . S$. patients having abnormal findings, compared to any of these tests alone, with $97 \%$ of "definite" M.S. patients, $86 \%$ of "probable" M.S. patients and $63 \%$ of "possible" M.S. patients having at least one of these EP tests abnormal.

patients sans atteinte clinique du système visuel $(45 \%$ des patients avec sclérose en plaques certaine, probable ou possible). Le $B A E P$, par contre, montra la plus basse fréquence d'anomalies chez les patients avec des signes du tronc cérébral $14 \%$ des patients avec sclérose en plaques). Lorsque l'on combine les 3 types de potentiels évoqués, ceci augmente le pourcentage des patients avec sclérose en plaques qui sont anormaux: ainsi $97 \%$ des patients "certains", $86 \%$ des "probables" et $63 \%$ des "possibles" ont au moins un test anormal.
From the Departments of Medicine, Division of Neurology. University of British Columbia, and Diagnostic Neurophysiology. Vancouver General Hospital.

Reprint requests to: Dr. S.J. Purves, Vancouver General Hospital, 855 West 12th Avenue, Vancouver. British Columbia, V5Z 1M9. Canada.

A preliminary version of these results was presented as a poster session at the XV Canadian Congress of Neurological Sciences in Ottawa. June 1980.
The patterned visual evoked potential (PVEP) has become a widely accepted test as an aid to the diagnosis of multiple sclerosis (MS) in its early stages. Halliday et al., (1972) first demonstrated that the latency of the PVEP was prolonged in patients with M.S. who did not have clinical evidence of a lesion in their optic nerves, thus providing objective evidence of multiple lesions at a time when the patient's presenting symptoms could be attributed to CNS involvement at a single location. This finding was received with great interest in many centers and numerous reports have appeared confirming the prolongation of the PVEP in patients with early M.S. (Halliday et al., 1973; Milner et al., 1974; Asselman et al., 1975; Hennerici et al., 1977; Zeese, 1977; Bynke et al., 1977 Purves \& Low, 1978; Collins et al., 1978; Shahrokhi et al. 1978). All of these later reports found somewhat lower percentages of abnormal responses than the $96 \%$ that Halliday had reported in his 51 patients. The results varied from a low of $57 \%$ in the patients with no history of optic neuritis in the series of Shahrokhi et al., (1978) to a high of $75 \%$ in Zeese (1977) and 76\% in Bynke et al. (1977) reports. The variability appeared related to the types of patients included in each series.

Robinson and Rudge (1975) reported that the brainstem auditory evoked potential (BAEP) was similarly effective in demonstrating lesions in the brainstem auditory pathways of M.S. patients and this finding was confirmed and the types of abnormalities were further defined by others (Chiappa and Norwood, 1977; Robinson and Rudge, 1977; Stockard and Rossiter, 1977; Chiappa, 1980).

Short latency somatosensory evoked potentials (SEPs) for upper limb (Eisen and Nudleman, 1978; 
Small et al., 1978; Eisen et al., 1979; Chiappa et al., 1980) and recently for lower limb stimulation (Eisen and Odusote, 1980) have also been shown to be delayed in multiple sclerosis patients with and without clinical involvement of this system. Documentation in an autopsy study of the sensitivity of the SEP in revealing a small plaque of demyelination that had not resulted in any clinical symptoms was reported by Matthews and Esiri (1979).

There have been a few reports of combining two or more of these evoked potential tests in individual patients. Mastaglia et al., (1976) combined SEPs and PVEPs to increase the abnormal percentage from $83 \%$ with PVEP alone to $94 \%$ with both tests in "definite" patients, and from $33 \%$ to $59 \%$ in the "possible" patients. Trojaborg and Petersen (1979) also reported improvement with combining PVEP and SEP tests. Chiappa (1980) was the first to provide a combination of all three types of sensory EPs in some of the patients from a large series.

This report outlines the results of the application of a uniform battery of evoked potential (EP) tests in a series of 112 patients studied in our laboratory over a 12 month period because of known or suspected M.S. (January 1, 1979 to December 31, 1979). The EP tests included the PVEP, short latency SEPs for median nerve stimulation, and BAEPs. The results were evaluated with consideration given to the diagnostic classification of M.S. for each patient by the McDonald and Halliday (1977) criteria, and also with respect to whether the patient had clinical signs or symptoms in any of the three systems tested.

\section{METHODS}

There were 112 patients referred for testing because of known or suspected M.S. A full neurological history and examination were available at the time of the referral, and on the basis of this information the patients were classified according to the criteria of McDonald and Halliday (1977). No patient with onset of symptoms after 50 years of age was included. There were 33 classified as clinically definite, 21 as early probable, 16 as suspected, 13 as progressive possible (progressive spinal paraplegia with other causes excluded) and 29 patients for whom M.S. was reasonably included in the differential diagnosis of their signs or symptoms, but who did not fall into any of the previous categories. This group we called "possibility". As described by McDonald and Halliday (1977), a patient classified as "suspected" had had a "single episode suggestive of M.S." with or without evidence of a single lesion. Patients with neurological symptoms that were not necessarily clearly episodic, or not typical for M.S., or for whom other causes were still being considered were included in our "possibility" group. Also 5 patients with first episodes of optic neuritis, and 3 patients with transverse myelitis were included in this "possibility" group.

The clinical presentation for each patient was classified as positive or negative for each of the three systems tested by the evoked potentials. Decreased corrected visual activity, an afferent pupil defect, visual scotoma, or a clear history of optic neuritis for either eye was classified as positive clinical evidence for optic nerve involvement (questionable optic disc pallor was not). Objective sensory changes, weakness or spasticity (but not a reflex asymmetry alone) in the upper limbs were considered as positive clinical evidence for a lesion that could be in the same areas tested by the SEPs and diplopia, internuclear ophthalmoplegia, cerebellar signs or marked nystagmus were all considered as clinical evidence of a possible brainstem lesion in the area tested by the BAEPs.

The EP testing was done with a Z-80 microprocessor-based system developed in our laboratory. This system incorporates a Grass S44 stimulator, and a 23 inch Electrohome television monitor for presentation of stimuli. The EEG was recorded with Grass P511J amplifiers and digitized (to 8 bit precision) at a rate of 200 points/epoch. No specialized averaging or math hardware was used. All EPs were replicated at least once.

PVEPs were elicited with a reversing checkerboard pattern generated on a T.V. screen. 100 trials were averaged with a stimulus rate of 1 /second. The pattern consisted of $1 \mathrm{~cm}$ checks viewed from 1 metre, and the total field size subtended $26^{\circ}$. The overall screen luminance was 12 ft-lamberts. The EEG was recorded with a bandpass of $1-300 \mathrm{~Hz}$ from an electrode (Grass gold disc) placed $5 \mathrm{~cm}$ above the inion at the midline referred to $F_{2}$. In 20 normal subjects, the mean latency of the major positive peak (called P100 by most investigators) was $93.6 \pm 3.25 \mathrm{msec}$, and the mean interocular latency difference was 2.0 $\pm 1.43 \mathrm{msec}$. The upper limit of normal (mean plus 3 SDS) used was $103 \mathrm{msec}$ for the Pl00 and $6 \mathrm{msec}$ for the interocular difference.

The SEPs were elicited with an electrical stimulus of $.2 \mathrm{msec}$ duration controlled by a Grass constant current stimulator. It was applied over the median nerve at the wrist and adjusted to just below the thenar muscle twitch threshold. The stimulating current was usually in the 3-7 $\mathrm{mA}$ range. The electrical activity for averaging was recorded on 3 channels: from the ipsilateral Erb's point, over the second cervical spine, and at the $\mathrm{C}_{3}$ or $\mathrm{C}_{4}$ site on the scalp (contralateral to the stimulated wrist), all referred to a reference placed on the mid forehead. Five hundred trials with a stimulus rate of $5 /$ second were averaged. A bandpass of 3-1000 Hz was used. Interpeak latencies were measured between the negative peak recorded at the Erb's point and the $\mathrm{N}_{14}$ recorded over the cervical spine (nomenclature described by Eisen et al., 1979), and between the Erb's point negative peak and the first negative peak $\left(\mathrm{N}_{20}\right)$ recorded over the contralateral scalp electrode. Normal studies conducted in our laboratory in 20 subjects showed a mean interpeak latency of $3.6 \pm .45 \mathrm{msec}$ from Erb's point to the cervical spine peak, and $9.2 \pm .6 \mathrm{msec}$ from Erb's point to the first negative peak (N1) at the scalp. For this study inter arm differences were not considered. The upper limit of normal (mean plus 3 SDs) used was $5.0 \mathrm{msec}$ for the latency to the cervical spine peak, and $11.0 \mathrm{msec}$ for the latency to the $\mathrm{N} 1$ peak recorded at the scalp.

Brainstem auditory evoked responses were elicited by $.2 \mathrm{msec}$ click stimuli at 65 $\mathrm{dB}$ above the patient's subjective threshold presented to the right and left ear separately. Two thousand trials with a stimulus rate of $10 /$ second were averaged. BAEPs were recorded from $\mathrm{Cz}$ referred to ipsilateral ear lobe with a bandpass of $100-$ $3000 \mathrm{~Hz}$. The I-III and I-V interpeak latencies were measured and the amplitude ratio of $I: V$ calculated for each ear. The normal values for these interpeak latencies determined in 20 subjects for our laboratory were similar to those reported by others (Rowe, 1978), i.e. for l-III the mean was $2.16 \pm .11$, and the upper limit (mean + 3 SDS) used was $2.6 \mathrm{msec}$, for $\mathrm{I}-\mathrm{V}$ the mean was $4.15 \pm .15$ and the upper limit (mean + 3SDS) used was $4.6 \mathrm{msec}$ and the $\mathrm{I} / \mathrm{V}$ amplitude ratio was considered abnormal if it was less than 1. Inter-ear latency differences do not appear useful because of the frequent occurrence of different configurations (and absolute latencies) of the peaks between ears in the normal subjects (Chiappa, 1979).

All of these tests could be completed in less than two hours for most patients. Once the patient was prepared, the PVEP 
required about 20 minutes, the SEPs another 30 - 40 minutes and the BAEPs 40 50 minutes of examination time. Waveforms were displayed on a monitor (or oscilloscope) and the peak latencies and amplitudes were measured with a digital cursor system. They were then written on an $X-Y$ plotter for later re-examination and filing.

\section{RESULTS}

The percentages of abnormal tests for the patients in each of the diagnostic categories are indicated in Table I. Some of the patients had more than one abnormal test and so the final column does not necessarily represent a summation of the three. The PVEP showed the highest abnormal rate with the SEP second and the BAEP the lowest rate in all of the diagnostic classifications.

In order to determine how frequently the EP tests detected lesions that were not evident from the clinical examination or history, a further

TABLE I:

Results of Multimodality Evoked Response Testing on 112 Patients

\begin{tabular}{|c|c|c|c|c|c|c|}
\hline & $\mathbf{n}$ & Mean Age & Abnormal PVEP & Abnormal SEP & Abnormal BAEP & $\begin{array}{l}\text { At least one } \\
\text { test abnormal }\end{array}$ \\
\hline Definite & (33) & 39 & $91 \%(30)$ & $67 \%(22)$ & $45 \%(15)$ & $97 \%(32)$ \\
\hline Probable & (21) & 37 & $76 \%(16)$ & $52 \%(11)$ & $14 \%(3)$ & $86 \%(18)$ \\
\hline Suspected & (16) & 36 & $38 \%(6)$ & $50 \%$ ( 8$)$ & $25 \%(4)$ & $63 \%(10)$ \\
\hline Progressive & (13) & 47 & $38 \%(5)$ & $46 \%(6)$ & $31 \%(4)$ & $54 \%(7)$ \\
\hline "Possibility" & (29) & 33 & $14 \%(4)$ & $10 \%(3)$ & $7 \%(2)$ & $28 \%(8)$ \\
\hline
\end{tabular}

TABLE II:

Evoked Potential Results Considered in Conjunction With Individual Clinical Information

\begin{tabular}{|c|c|c|c|c|}
\hline & Positive & Confirmatory & Paradoxical & Negative \\
\hline \multicolumn{5}{|l|}{ DEFINITE (33) } \\
\hline PVEP & $42 \%(14)$ & $48 \%(16)$ & $3 \%(1)$ & $6 \%(2)$ \\
\hline SEP & $39 \%(13)$ & $27 \%(9)$ & $3 \%(1)$ & $30 \%(10)$ \\
\hline BAEP & $12 \%(4)$ & $33 \%(11)$ & $30 \%(10)$ & $24 \%(8)$ \\
\hline \multicolumn{5}{|l|}{ PROBABLE (21) } \\
\hline PVEP & $67 \%(14)$ & $10 \%(2)$ & $0 \%(0)$ & $24 \%(5)$ \\
\hline SEP & $29 \%(6)$ & $24 \%(5)$ & $19 \%(4)$ & $29 \%(6)$ \\
\hline BAEP & $5 \%(1)$ & $10 \%(2)$ & $38 \%(8)$ & $48 \%(10)$ \\
\hline \multicolumn{5}{|l|}{ SUSPECTED (16) } \\
\hline PVEP & $25 \%(4)$ & $12 \%(2)$ & $0 \%(0)$ & $62 \%(10)$ \\
\hline SEP & $44 \%(7)$ & $6 \%(1)$ & $0 \%(0)$ & $50 \%(8)$ \\
\hline BAEP & $19 \%(3)$ & $6 \%(1)$ & $12 \%(2)$ & $62 \%(10)$ \\
\hline \multicolumn{5}{|c|}{ PROGRESSIVE (SPINAL) (13) } \\
\hline PVEP & $38 \%(5)$ & $0 \%(0)$ & $0 \%(0)$ & $61 \%(8)$ \\
\hline SEP & $23 \%(3)$ & $23 \%(3)$ & $8 \%(1)$ & $18 \%(6)$ \\
\hline BAEP & $31 \%(4)$ & $0 \%(0)$ & $0 \%(0)$ & $69 \%$ ( 9$)$ \\
\hline \multicolumn{5}{|l|}{ POSSIBILITY (29) } \\
\hline PVEP & $7 \%(2)$ & $7 \%(2)$ & $0 \%(0)$ & $86 \%(25)$ \\
\hline SEP & $3 \%(1)$ & $0 \%(0)$ & $0 \%(0)$ & $96 \%(28)$ \\
\hline BAEP & $3 \%(1)$ & $0 \%(0)$ & $3 \%(1)$ & $93 \%(27)$ \\
\hline \multirow[b]{3}{*}{ (112) BAEP } & $34 \%(39)$ & $20 \%(22)$ & $1 \%(1)$ & $45 \%(50)$ \\
\hline & $27 \%(30)$ & $16 \%(18)$ & $5 \%(6)$ & $52 \%(58)$ \\
\hline & $11 \%(13)$ & $12 \%(14)$ & $19 \%(21)$ & $57 \%(64)$ \\
\hline
\end{tabular}


analysis of the individual patient's results was made. The results of each of the three EP tests were classified as positive if the EP did detect an abnormality that was not indicated by the clinical examination (as defined in the methods section), confirmatory if an abnormal EP only confirmed positive findings from the clinical examination, paradoxical if the EP was normal in the presence of abnormal clinical signs in the same system and negative when both the EP and clinical exam were normal. The results of this classification for each of the diagnostic categories are shown in Table II.

These figures indicate that of the three, the PVEP most frequently detects subclinical lesions $(34 \%$ abnormal in the total group of patients). The SEP appeared to be slightly less sensitive for subclinical lesions (27\% of the patients) and the BAEP was abnormal in the smallest percentage of the patients $(11 \%)$. This relationship was present in nearly all of the diagnostic groups (with the exception of the progressive-spinal group where the BAEP detected subclinical lesions in a slightly higher percentage of patients than the SEP). If the "possibility" patient group is excluded from the overall total (since the likelihood of subclinical lesions existing in this group is much lower) the frequency of detecting subclinical lesions in the remaining patients is increased to $45 \%$ for the PVEP, 35\% for the SEP and $14 \%$ for the BAEP. Table II also shows that the incidence of "paradoxical" findings for the PVEP is extremely low, with only one patient in the entire series showing a normal PVEP in the presence of a definite history of optic neuritis. There was also one other patient who presented with transverse myelitis, was noted to have a normal PVEP at that time, but who developed optic neuritis within a few weeks following testing. Repeat testing several months later following recovery from the episode of optic neuritis showed an abnormal PVEP, but repeat examinations on the same patient were not included in this series.

\section{DISCUSSION}

The observation that the PVEP is more sensitive for subclinical lesions, and more frequently abnormal in the total group of patients is in agreement with the study of Trojaberg and Petersen (1979). Chiappa (1980) and Mastaglia et al. (1976) reported that the SEP was abnormal in a slightly higher percentage of M.S. cases than the PVEP. The differences between these studies and ours are not large however, and may be due to variations in the patient series. In this study and also in those of Chiappa (1978) and Mastaglia (1976) the latency differences between right and left side were not included in the normal criteria for SEPs. Eisen (1979) has suggested that these symmetry differences should be considered and that this would significantly increase the rate of abnormal SEP findings in M.S. patients.

The relatively low percentages of abnormal BAEPs in these patients and the high increase of "paradoxical" results with the BAEPs may be due to several factors. Because the pathway tested by the BAEP is a very short one it is perhaps less likely to contain demyelinating plaques than the longer myelinated tracts tested by the PVEP and SEP. The clinical signs that may result from lesions in the vicinity of the brainstem auditory pathways are not necessarily specific to this location; for example signs such as nystagmus or cerebellar ataxia may result from lesions in the brainstem or cerebellum and this may account for the high incidence of "paradoxically" normal BAEPs.

The diagnostic classification of patients with M.S. is sometimes difficult. We choose to use the criteria laid out by McDonald and Halliday (1977) because they are slightly broader than those of McAlpine (1972). Since one of the important questions is whether these EP tests are useful in the assessment of patients in very early stages of M.S., it seems essential to have some way of classifying all of the patients who are tested with the possibility of this diagnosis under consideration. This inclusion of the group of patients we have called "possibility" in this series makes it unique. The EPs in these patients can serve to provide objective evidence of mild neurological symptoms difficult to document with clinical examination, and may also provide evidence of lesions otherwise not suspected, thus indicating a more widespread disease process. The abnormality rate in this particular group in our series was found to be very low. The percentage of these patients that eventually prove to have multiple sclerosis in spite of normal findings at the initial examination will be determined with a later long-term followup study.

This multimodality evoked potential approach appears to show abnormal results in a larger number of patients with known or suspected M.S. than any of the EP tests used alone. A comparison of the individual EP results shows that with our current techniques PVEP provides the highest yield for detecting subclinical demyelinating lesions with the SEP slightly lower and the BAEP showing the lowest detection rate.

\section{ACKNOWIEDGEMENTS}

The development of the microprocessor unit for the evoked potential testing wats done with the assistance of Michael Baker. B.A.Sc. The research was supported by grants from the M.S. Society of Canada and the B.C. Health Care Rescarch Foundation.

\section{REFERENCES}

ASSELMAN, P.. CHADWICK, D.W., and MARSDEN, C.D. (1975) Visual evoked responses in the diagnosis and management of patients suspected of multiple sclerosis. Brain, 98: 261-282

BYNKE, H., OL.SSON, J.E., and ROSEN, I (1977) Diagnostic value of visual evoked response, clinical eye examination and CSF analysis in chronic myelopathy. Acta. Neurol. Scand, 56: 55-69.

CHIAPPA, K.H. and NOR WOOD. A.E. (1977) $A$ comparison of the clinical utility of pattern-shift visual evoked responses and brainstem auditory evoked responses in multiple sclerosis. Neurology (Minneap), 27 : 397.

CHIAPPA, K.H., GLADSTONE, K.J., and YOUNG, R.R. (1979) Brainstem auditory evoked responses: studies of waveform variations in 50 normal human subjects. Arch. Neurol., 36: 81-87.

CHIAPPA, K.H. (1980) Pattern shift visual, brainstem auditory and short-latency somatosensory evoked potentials in multiple sclerosis. Neurology, 30: 110-123.

CHIAPPA. K.H., CHOl, S., and YOUNG, R.R. (1980) Short latency somatosensory evoked potentials following median nerve stimulation in patients with neurological lesions. In: Desmedt, J.E. (Ed) Clinical Uses of Cerebral, Brainstem and Spinal Somatosensory Evoked Potentials. Prog. clin. Neurophysiol., 7: 264-281. 
CHIAPPA, K.H., HARRISON, J.L., BROOKS, E.B., and YOUNG, R.R (1980) Brainstem auditory evoked responses in 200 patients with multiple sclerosis. Ann. Neurol.. 7: 135143.

COLI.INS. D.W.K.. BI.ACK. J.L. and MASTAGLIA, F.L. (1978) Pattern-reversal visual potential: method of analysis and results in multiple sclerosis. J. Neurol. Sci., 36: 8395 .

EISEN, A. and NUDLEMAN, K. (1978) F wave and cervical somatosensory response conduction from the seventh cervical spinous process to cortex in multiple sclerosis. Can. J. Neurol. Sci., 5: 289-295.

EISEN, A., STEWART, J., NUDLEMAN, K. and COSGROVE, J.B.R. (1979) Shortlatency somatosensory responses in multiple sclerosis. Neurology, 29: 827-834.

EISEN, A., and ODUSOTE. K. (1980) Central and Peripheral conduction times in multiple sclerosis. Electroenceph. clin. Neurophysiol., 48: 253-265.

HALLIDAY, A.M., McDONALD, W.I., and MUSHIN, J. (1973) Visual evoked response in diagnosis of multiple sclerosis, B.M.J., 4: 661-664.

HALLIDAY, A.M., McDONALD, W.I., and MUSHIN, J. (1972) Delayed pattern-evoked responses in optic neuritis in relation to visual acuity. Trans. Ophthalmol. Soc., UK, 93: 315-324.
HENNERICl, M., WENZEL, D., and FREUND, H.J. (1977) The comparison of small-size rectangle and checkerboard stimulation for the evaluation of delayed visual evoked responses in patients suspected of multiple sclerosis. Brain, 100: 119-136.

McALPINE, D.. LUMSDEN. C.E.. ACHESON. E.D., (1972) Multiple Sclerosis: A Reappraisal. Edinburgh, Churchill Livingstone, Ltd.

MCDONALD, W.I. and HALLIDAY, A.M. (1977) Diagnosis and classification of multiple sclerosis, B. Med. Bull. 33: 4 - 8.

MASTAGLIA, F.L., BLACK, J.L., and COLLINS, D.W.K. (1976) Visual and spinal evoked potentials in diagnosis of multiple sclerosis, B.M.J., 2: 732.

MATTHEWS, W.B. and ESIRI, M. (1970) Multiple sclerosis plaque related to abnormal somatosensory evoked potentials. J. Neurol. Neurosurg. Psychiat., 42: 940-492.

MILNER, B.A., REGAN, D., and HERON, J.R. (1974) Differential diagnosis of multiple sclerosis by visual evoked potential recording. Brain, 97: 755-772.

PURVES, S.J. and LOW, M.D. (1978) The pattern VEP in the early stages of the diagnosis of M.S.: A prospective study. Can. J. Neurol. Sci., 5: 350.

ROBINSON, K. and RUDGE, R. (1975) Auditory evoked responses in multiple sclerosis. Lancet (i). 1164-1166.
ROBINSON, K. and RUDGE, P. (1977) Abnormalities of the auditory evoked potentials in patients with multiple sclerosis. Brain. 100: 19-40.

ROWE, M.J. (1978) Normal variability of the brainstem auditory evoked response in young and old adult subjects. Electroenceph. clin. Neurophysiol., 44: 459-470.

SHAHROKHI. F., CHIAPPA, K.H., and YOUNG, R.R. (1978) Pattern shift visual evoked responses. Two hundred patients with optic neuritis and/or multiple sclerosis. Arch. Neurol., 35: 65-71.

SMALL, D.G., MATTHEWS, W.B., and SMALL, M. (1978) The cervical somatosensory evoked potential (SEP) in the diagnosis of multiple sclerosis. J. Neurol. Sci., 35: 211274.

STOCKARD, J.J. and ROSSITER, V.S. (1977) Clinical and pathologic correlates of brainstem auditory response abnormalities. Neurology, 27: 316-325.

TROJABORG. W. and PETERSEN, E. (1979) Visual and somatosensory evoked cortical potentials in multiple sclerosis. J. Neurol. Neurosurg. Psychiat., 42: 323-330.

ZEESE, J.A. (1977) Pattern visual evoked responses in multiple sclerosis. Arch. Neurol., 34: 314-318. 